\title{
Risk Factors for the Development of Hepatocellular Carcinoma in Thailand
}

\author{
Taned Chitapanarux*1 and Kannika Phornphutkul ${ }^{1,2}$ \\ ${ }^{1}$ Division of Gastrohepatology, Department of Internal Medicine, Faculty of Medicine, Chiang Mai University, Chiang Mai, Thailand; \\ ${ }^{2}$ Gastrohepatology unit, Rajavej Chiang Mai Hospital, Chiang Mai, Thailand
}

\begin{abstract}
Hepatocellular carcinoma ( $\mathrm{HCC}$ ) is the most common type of liver cancer worldwide. The incidence of HCC is on the rise in Thailand, where it has become the most common malignancy in males and the third most common in females. Here, we review some of the risk factors that have contributed to this increase in HCC incidence in the Thai population. Hepatitis B virus (HBV) is the main etiologic risk factor for HCC, followed by hepatitis $\mathrm{C}$ virus (HCV). Patients with HBV genotype $\mathrm{C}$ have a higher positive rate of hepatitis $B$ early antigen ( $\mathrm{HBeAg}$ ) and progress to cirrhosis and HCC earlier than genotype B. For HCV patients, $16 \%$ developed HCC associated cirrhosis by year 5 after diagnosis, and the cumulative risk for death from $\mathrm{HCC}$ at year 10 was $60 \%$. Dietary exposure to the fungal hepatocarcinogen aflatoxin B1 has been shown to interact synergistically with $\mathrm{HBV}$ infection to increase the risk of early onset HCC. Chronic alcohol abuse remains an important risk factor for malignant transformation of hepatocytes, frequently in association with alcohol-induced cirrhosis. In recent years, obesity and metabolic syndrome have markedly increased the incidence of HCC and are important causes of $\mathrm{HCC}$ in some resource-rich regions.

(C) 2015 The Second Affiliated Hospital of Chongqing Medical University. Published by XIA \& HE Publishing Ltd. All rights reserved.
\end{abstract}

\section{Introduction}

Thailand is a developing country located in Southeast Asia. Laos and Cambodia are to its east, the Gulf of Thailand and Malaysia are to its south, and the Andaman Sea and Myanmar are to its west. The climate of the country as a whole is tropical and characterized by monsoons. According to

Keywords: Risk factors; Hepatocellular carcinoma; Etiology.

Abbreviations: AFB1, aflatoxin B1; ALT, alanine aminotransferase; ASR, agestandardized incidence rate; $\mathrm{CHB}$, chronic hepatitis $\mathrm{B}$; $\mathrm{CHC}$, chronic hepatitis $\mathrm{C}$ $\mathrm{DM}$, diabetes mellitus; $\mathrm{HBeAg}$, hepatitis $\mathrm{B}$ virus early antigen; $\mathrm{HBsAg}$, hepatitis $\mathrm{B}$ virus surface antigen; $\mathrm{HBV}$, hepatitis $\mathrm{B}$ virus; $\mathrm{HCC}$, hepatocellular carcinoma; $\mathrm{HCV}$, hepatitis C virus; HDV, hepatitis D virus; IARC, International Agency for Research on Cancer; IGF1, insulin-like growth factor-1; IL-6, interleukin-6; IRS-1, insulin receptor substrate-1; JNK1, c-Jun amino-terminal kinase 1 ; NAFLD, non-alcoholic fatty liver disease; NASH, non-alcoholic steatohepatitis; ROS, reactive oxygen species; TNF- $\alpha$, tumor necrosis factor-alpha.

Received: 29 July 2015; Revised: 25 August 2015; Accepted: 28 August 2015

DOI: $10.14218 / \mathrm{JCTH} .2015 .00025$.

*Correspondence to: Taned Chitapanarux, Division of Gastrohepatology, Department of Internal Medicine, Faculty of Medicine, Chiang Mai University, Chiang Mai 50200, Thailand. Tel: +66-53-945482, Fax: +66-53-945481, E-mail: thaitaned@yahoo.com estimates of the National Caner Register in Thailand, the number of new cancer cases in 2008 was 50,966 males and 51,825 females. ${ }^{1}$ These values correspond to agestandardized incidence rates (ASR) of 156.7 per 100,000 for males and 138.2 per 100,000 for females. Liver and bile duct cancer was the most common cancer $(\mathrm{ASR}=40.6)$ in males followed by lung and colorectal cancer. In females, breast cancer was the most common $(A S R=26.4)$, followed by cervical cancer and liver and bile duct cancer, as shown in Fig. 1. The annual incidence of liver and bile duct cancer was 40.3 per 100,000 in males and 16.6 per 100,000 in females. In Thailand, liver cancer is the third leading cause of death from malignant neoplasms in males, following lung and stomach cancer. In females, liver cancer ranked fifth as a cause of death during the past decade, following colon, stomach, lung, and breast cancer. Primary liver cancer can be classified into three types, according to the cell from which the cancer originated: hepatocellular carcinoma (HCC), cholangiocarcinoma, and other.

$\mathrm{HCC}$, which is associated with hepatitis B virus (HBV), is a major problem in all regions of Thailand, with the exception of Khon Kaen and the Northeast. Liver flukes, related to cholangiocarcinoma, account for about $89 \%$ of all liver cancers in Khon Kaen, which has the highest incidence rate of liver cancer in the world (ASR=97.4 in males and 39.0 in females). ${ }^{2}$ The number of new patients with HCC in Thailand is shown in Table 1. HCC was the first human cancer shown to be amenable to prevention using mass vaccination programs. From a global prospective, the burden of chronic HBV infection is expected to decline because of the increased use of HBV immunization since the early 1980 s. National infant vaccination against HBV began in 1992 in Thailand; ${ }^{3}$ although the number of patients with $\mathrm{HCC}$ in the $21^{\text {st }}$ century is greater than that from the 1990s. Vaccine recipients are still too young to have their rates greatly affect the rates in the overall population. Health workers and other high-risk groups are not vaccinated in sufficient numbers. In males, the Thai ASR global ASRs for HCC were 40.3, 42.8, 36.8, and 31.2 in 2008, 2006, 2003, and 1999, respectively. This increase in HCC incidence may be due to several factors, such as improved diagnosis of these patients, better management leading to increased survival, and lower mortality.

\section{Risk factors for HCC}

HCC is a complex disease associated with many risk factors and cofactors. The major risk factor for the development of HCC is cirrhosis of the liver, and, not surprisingly, common 
Chitapanarux T. et al: Risk factors for hepatocellular carcinoma
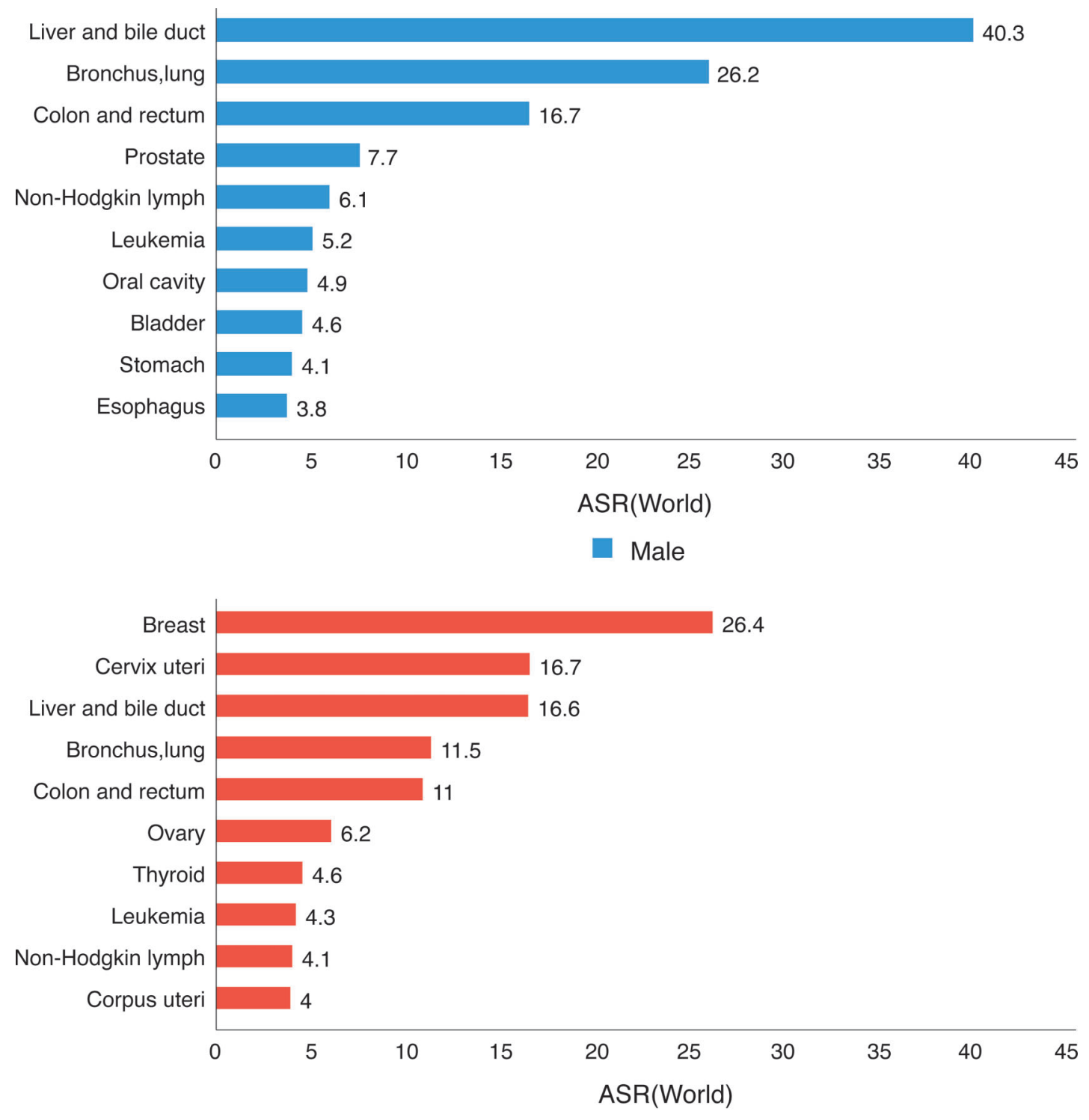

Female

Fig. 1. Leading cancer in Thailand (estimated), 2008.

Table 1. Thailand frequency of new cases of hepatocellular carcinoma

\begin{tabular}{lccr}
\hline Year & Total number & Males (ASR, world) & Females (ASR, world) \\
\hline 2008 & 19,424 & $13,281(40.3)$ & $6,143(16.6)$ \\
$2004-2006$ & 59,123 & $39,884(42.8)$ & $19,239(18.2)$ \\
$2001-2003$ & 47,439 & $33,313(36.8)$ & $14,126(15.1)$ \\
1999 & 11,382 & $8,298(31.2)$ & $3,094(11.5)$ \\
\hline
\end{tabular}

Adapted from Cancer in Thailand. ${ }^{1}$ ASR, age-standardized incidence rate.

causes of cirrhosis have been identified as key risk factors for HCC. However, approximately one-quarter of HCC cases diagnosed in Thailand were not linked with any predisposing risk factors. The major known risk factors for HCC can be divided into four categories: viral (chronic hepatitis B and hepatitis C), toxic (alcohol and aflatoxins), metabolic (diabetes and non-alcoholic fatty liver disease, hereditary hemochromatosis), and immune-related (primary biliary cirrhosis and autoimmune hepatitis). The geographical variability in the incidence of HCC has been attributed to changes 
in the natural history and distribution of HBV and hepatitis $\mathrm{C}$ virus (HCV) infections. It has been estimated that $\mathrm{HBV}$ and $\mathrm{HCV}$ are responsible for $50-80 \%$ and $10-25 \%$, respectively, of HCC cases worldwide. ${ }^{4}$ In Thailand, the main etiologic risk factor in $\mathrm{HCC}$ is $\mathrm{HBV}^{5}$ with a lesser role for $\mathrm{HCV}^{6}$

\section{HBV}

The World Health Organization (WHO) has reported that HBV, second only to tobacco, is a human carcinogen. HBV is a DNA hepadnavirus, and it is transmitted by perinatal, parenteral, and sexual exposure. In highly endemic areas, such as Eastern Asia, China, and Africa, approximately $70 \%$ of HBV infections are acquired either perinatally or in early childhood. ${ }^{7}$ Perinatal exposure leads to chronic infection in $90-95 \%$ of cases, while childhood exposure leads to chronic hepatitis B (CHB) in $50 \%$ of cases. The lifetime risk of cirrhosis is $20-30 \%$ in perinatal and childhood infections. In low prevalence areas, such as Australia, North America, and Western Europe, HBV is acquired primarily in adulthood through sexual contact or intravenous drug use. Approximately $95 \%$ of adults acutely infected with $\mathrm{HBV}$ will clear the infection and develop immunity to HBV. ${ }^{8}$ $\mathrm{HCC}$ develops in $0.5-0.8 \%$ per annum in patients with $\mathrm{CHB}$ compared with $1.4-2.5 \%$ in those with cirrhosis secondary to $\mathrm{CHB} .{ }^{9}$ The annual risk for developing $\mathrm{HCC}$ is $0.5 \%$ for asymptomatic hepatitis $B$ virus surface antigen (HBsAg) carriers and $0.8 \%$ for patients with chronic hepatitis B. Patients with HBV-cirrhosis are at 1000 times greater risk for developing $\mathrm{HCC}$ than HBsAg negative individuals. ${ }^{10}$ Thus, it appears that the likelihood of acquiring HCC increases as the severity of the underlying liver disease increases. Since most people in Asia with HBV are infected at birth, age on onset of HBV-related cirrhosis is usually earlier than in Western Europe or North America.

There is strong epidemiological data in support of a causal relationship between $\mathrm{CHB}$ and $\mathrm{HCC}$. Worldwide, regional variation in the incidence of $\mathrm{HCC}$ mirrors the prevalence of $\mathrm{CHB}$ in the local population. ${ }^{11}$ In highly endemic countries with successful immunization programs, such as Taiwan, there has been a decline in both the prevalence of $\mathrm{CHB}$ and the incidence of $\mathrm{HCC}^{12}$

\section{HBV factors in HBV-related HCC}

The mechanisms underlying carcinogenesis in HBV infection have been extensively studied. A major contributing factor is chronic necroinflammation and subsequent fibrosis and hepatocyte proliferation. In $20 \%$ of cases in the developed world and $40 \%$ in sub-Saharan Africa and China, however, HCC occurs in noncirrhotic livers. ${ }^{13}$ The contribution of hepatocellular injury and fibrosis in noncirrhotic patients with $\mathrm{CHB}$ and $\mathrm{HCC}$ is difficult to quantify, but there is evidence that HBV is directly oncogenic. HBV DNA integrates into the host genome, leading to alterations in cellular signaling and growth control. Both HBV and host hepatocytes may contribute to the final pathogenic outcome, either individually or synergistically. HBV may encode oncogenic viral proteins that contribute to hepatocarcinogenesis. HBV encoded $X$ antigen $(\mathrm{HBX})$ is a viral nonstructural gene that is a multifunctional regulator modulating gene transcription and controlling cell responses to genotoxic stress, protein degradation, apoptosis, and several signaling pathways. ${ }^{14}$ The cellular immune response against infected hepatocytes, combined with long-term toxic effects of viral gene products, trigger chronic necroinflammation with subsequent fibrosis and hepatocyte proliferation, increasing the likelihood of malignant transformation.

\section{HBV genotype and viral load in hepatocarcinogenesis}

Several viral factors in addition to viral proteins, such as viral genotype and viral load, have been associated with hepatocarcinogenesis. Eight HBV genotypes $(\mathrm{A}-\mathrm{H})$ based on genomic sequence divergence have been described. These genotypes have distinct geographical and ethnic distributions: genotypes $A$ and $D$ are found in Africa, Europe, and India; genotype $B$ and $C$ are in Asia; genotype $E$ is found only in West Africa; and genotype $F$ is present in Central and South America. It has been reported that HBV genotype affects clinical outcome and responses to therapy. In Asia, genotype C has been linked to more severe liver disease, cirrhosis, and the development of HCC than genotype B. In Western Europe and North America, genotype $D$ has been associated with more severe liver disease and a higher incidence of HCC than genotype A. ${ }^{15}$ The predominant HBV genotypes in Thailand are $C$ and $B$, accounting for $73 \%$ and $21 \%$, respectively. The distribution of genotypes $B$ and $C$ were similar in HCC patients compared to patients with chronic hepatitis or cirrhosis. Patients with genotype $C$ had a higher positive rate of hepatitis $B$ virus early antigen $(\mathrm{HBeAg})$ and exhibited earlier progression to cirrhosis and HCC than genotype B. However, as shown in Table 2, there were no differences in the risk of developing $\mathrm{HCC}$ and its prognosis. ${ }^{16}$

Serum HBV DNA levels across a biological gradient appear to be a strong predictor for the risk of disease progression and the development of $\mathrm{HCC}$, independent of $\mathrm{HBeAg}$ status, serum alanine aminotransferase (ALT) level, and liver cirrhosis. ${ }^{17}$ Based on a community survey, it was found that Taiwanese patients were 10 times more likely to develop HCC if HBV DNA was persistently $>20,000 \mathrm{IU} / \mathrm{mL}$ than if HBV DNA was $<2,000 \mathrm{IU} / \mathrm{mL}$. Those patients with a serum HBV DNA titer of 2,000 IU/mL were at increased risk for developing HCC relative to healthy controls. ${ }^{18}$

Table 2. Clinical diagnosis of $\mathrm{HBV}$ cases

\begin{tabular}{|c|c|c|c|c|c|c|c|c|}
\hline \multirow[b]{2}{*}{ Diagnosis } & \multirow[b]{2}{*}{$\mathrm{N}$} & \multirow[b]{2}{*}{$\operatorname{Sex}(M / F)$} & \multirow[b]{2}{*}{ Age (yr) } & \multirow[b]{2}{*}{ HBeAg: positive (\%) } & \multicolumn{4}{|c|}{ Genotype (\%) } \\
\hline & & & & & A & B & $\mathrm{C}$ & $U$ \\
\hline Carrier & 93 & $57 / 36$ & $30.9 \pm 10.6$ & 51.2 & 2.2 & 17.2 & 78.4 & 2.2 \\
\hline $\mathrm{CH}$ & 103 & $84 / 19$ & $36.2 \pm 10.1$ & 66.3 & 4.9 & 19.4 & 73.8 & 1.9 \\
\hline Cirrhosis & 60 & $47 / 13$ & $48.8 \pm 13.8$ & 49.1 & 3.3 & 16.7 & 73.3 & 6.7 \\
\hline $\mathrm{HCC}$ & 76 & $60 / 16$ & $54.4 \pm 12.9$ & 21.1 & 2.6 & 30.3 & 65.8 & 1.3 \\
\hline
\end{tabular}




\section{Co-infection of HBV and hepatitis D virus (HDV)}

HDV co-infection with HBV is associated with increased liver damage. Verme and coworkers showed that HBsAg positive patients with HDV superinfection developed cirrhosis and HCC at an earlier stage (mean age 48 years) compared to $\mathrm{HBsAg}$ carrier without HDV infection (mean age 62 years). ${ }^{19}$

\section{HCV}

$\mathrm{HCV}$ is a positive single-stranded RNA flavivirus, and its mode of transmission is predominantly parenteral. Most people infected with HCV (up to $80 \%$ ) are unable to spontaneously eliminate the virus and progress to chronic hepatitis $\mathrm{C}$ $(\mathrm{CHC}){ }^{20} \mathrm{CHC}$ is the causative agent in the majority of HCC in developed countries, where up to $70 \%$ of patients with $\mathrm{HCC}$ have anti-HCV antibodies in serum. ${ }^{21}$ The risk of HCC in $\mathrm{CHC}$ is $1.2-1.7 \%$ per annum in patients with underlying chronic hepatitis and $1.4-2.5 \%$ per annum in those with cirrhosis. $^{22}$

The prevalence of HCV infection varies considerably by geographical region. African and Asian countries have a relatively high prevalence rate compared to North America, Europe, and Australia. ${ }^{20}$ Egypt has the highest prevalence of $\mathrm{HCV}$ in the world (predominantly genotype 4), which has been attributed to previous public health schemes for schistosomiasis. ${ }^{23} \mathrm{HCV}$ infection rates, up to $60 \%$, have been reported in older individuals who live in rural areas, such as the Nile delta, and in lower social classes.

Several studies have investigated the natural history of $\mathrm{HCV}$ infection. In Japan, ${ }^{24}$ a time lag of 13 years was reported from infection by transfusion of HCV infected blood to the development of chronic hepatitis. This time period was estimated to be 10 years in an American study, where it took about 20 years for the same patients to develop cirrhosis of the liver. ${ }^{25}$ Development of HCC took 28 years in the American subjects and 29 years in the Japanese cohort. The annual risk for developing $\mathrm{HCC}$ depends on the presence and severity of the underlying liver disease.

In HCV infection, viral RNA is not reverse transcribed into DNA, and, thus, it does not integrate into the host genome. In $\mathrm{CHC}, \mathrm{HCC}$ almost always arises in the setting of cirrhosis. The likely mechanism of hepatocarcinogenesis involves chronic necroinflammation, cellular regeneration, fibrosis, and subsequent progression to cirrhosis, which promotes genomic damage. ${ }^{26}$ The rate of fibrotic progression following HCV infection is highly variable, as the natural history of the disease typically extends over several decades. Factors that influence the rate of fibrotic progression in HCV-infected patients are age at the time of infection, male gender, $\mathrm{HCV}$ genotype, and alcohol consumption. It remains unclear whether any of these factors affect the onset of liver-related complications by mechanisms other than their effects on the rate of fibrotic progression. To determine which interactive variables were independent determinants of adverse clinical outcomes, Khan and colleagues examined the development of liver-related complications with chronic HCV in a large cohort of patients who were heterogeneous in age, country of birth, mode of HCV acquisition, HCV genotype, and histological and functional severity of liver disease. Patients were followed-up for 5 years. The major independent predictors of liver-related complications identified in this study were sporadic transmission, advanced liver fibrosis at entry, and low albumin. ${ }^{27}$

The prevalence of $\mathrm{HCV}$ in the adult population in Thailand is $2.7 \%(1.8-3.7 \%) .{ }^{28}$ In a long term study greater than 5 years, Punyagupta and colleagues reported that $16 \%$ of HCV patients developed HCC associated cirrhosis, which was much a higher percentage than that of $\mathrm{HBV}$, as shown in Table 3. The cumulative risk for death from $\mathrm{HCC}$ at year 10 after HCV diagnosis was $60 \%{ }^{29}$ In Thailand, HCV infection is a major risk factor for the development of HCC.

\section{Combined hepatitis B and hepatitis C}

Follow-up studies have shown that patients with combined $\mathrm{HCV}$ and $\mathrm{HBV}$ infection have a higher risk of developing HCC than those with $\mathrm{HCV}$ and $\mathrm{HBV}$ alone. The cumulative $\mathrm{HCC}$ risk was $10 \%, 21 \%$, and $23 \%$ after 5 years and $16 \%, 28 \%$, and $45 \%$ after 10 years for HCV, HBV, and their combination, respectively. ${ }^{30}$ The HCC risk in subjects with both infections was investigated in a meta-analysis of 32 epidemiological studies between 1993 and 1997. ${ }^{31}$ The OR for development of $\mathrm{HCC}$ in HBsAg positive and anti-HCV/HCV RNA negative subjects was 20.4; in $\mathrm{HBsAg}$ negative and anti-HCV/HCV RNA positive subjects, it was 23.6 ; and in subjects positive for both markers, the OR was 135.0 . These data suggested the effect of HBV and HCV co-infection on HCC risk was more than additive. The two viruses may act through both common and distinct pathways in the carcinogenic process. Since HBV acts as a cofactor in the development of HCV related cirrhosis and $\mathrm{HCC}$, vaccination of patients with $\mathrm{CHC}$ against $\mathrm{HBV}$ has been recommended to avoid additional liver injury.

\section{Coinfection with human immunodeficiency virus (HIV)}

The course of $\mathrm{CHC}$ is more aggressive in HIV positive subjects, leading to cirrhosis and liver failure in a shorter time period. Co-infection with HIV frequently occurs because

Table 3. The first and final clinical diagnosis of HCV cases

\begin{tabular}{|c|c|c|c|c|c|}
\hline \multirow[b]{2}{*}{ First clinical diagnosis } & \multirow[b]{2}{*}{$\mathrm{N}$} & \multicolumn{4}{|c|}{ Late clinical diagnosis } \\
\hline & & Mild hepatitis & $\mathrm{CAH}$ & Cirrhosis & $\mathrm{HCC}$ \\
\hline Acute hepatitis & 20 & 9 & 5 & 2 & $4(20 \%)$ \\
\hline Mild hepatitis & 30 & 25 & 3 & - & $2(6.7 \%)$ \\
\hline $\mathrm{CAH}$ & 7 & 2 & 3 & - & $2(28.6 \%)$ \\
\hline Cirrhosis & 6 & - & - & 4 & $2(33.3 \%)$ \\
\hline Total & 63 & 36 & 11 & 6 & $10(15.9 \%)$ \\
\hline
\end{tabular}

$\mathrm{CAH}$, chronic active hepatitis; HCC, hepatocellular carcinoma. 
of shared routes of transmission. A recent study of HCC in $\mathrm{HIV}$-HCV co-infected patients indicated rapid development of HCC in these patients. ${ }^{32}$

\section{Alcohol}

Consistent with its significant role in cirrhosis, alcohol consumption contributes to $15 \%$ to $45 \%$ of HCC cases in developed countries. ${ }^{33}$ Many studies have demonstrated a significant link between heavy alcohol intake $(>50-70 \mathrm{~g} / \mathrm{d}$ for several years) and $\mathrm{HCC}^{34,35}$ where males tend to consume more alcohol than females. The annual incidence of HCC due to alcohol cirrhosis is $1-4 \% .{ }^{36}$ In contrast to American and European countries, alcohol consumption plays a minor role in HCC development in Asia. This is more true for Middle Eastern countries, where the consumption of alcohol is very low, than southeast Asia.

\section{Role of Aflatoxin AFB1}

Aflatoxin exposure is a major risk factor for developing HCC in particular regions where exposure to HBV is endemic. Aflatoxins are fungal toxins produced by Aspergillus flavus and Aspergillus parasiticus, which can contaminate staple foods, including groundnuts (peanuts). Storage of crops in hot humid conditions can promote the growth and accumulation of aflatoxin-producing fungi. Aflatoxin B1 (AFB1), the most abundant form, is metabolized by $\mathrm{P} 450$ enzymes in the liver to generate an epoxide that is highly reactive with DNA, forming adducts at the N7 position of guanine. If this lesion is not repaired, permanent DNA mutations may form, preferentially $G$ to $T$ transversions. A hotspot for AFB1induced mutations was identified at codon 249 in the TP53 suppressor gene (AGG to AGT, arginine to serine, R249S). Recent evidence confirmed that this position is a preferential site for AFB1 adduct formation. ${ }^{37}$

In Thailand, the main dietary sources of AFB1 are maize and groundnuts. Individual exposure to AFB1 has been estimated to range from 53 and $73 \mathrm{ng} / \mathrm{kg} /$ day, although this figure is likely to vary widely among different geographic areas and ecological zones. The HCC risk attributable to aflatoxin for Thailand was recently shown to be 0.5-0.7 and $15.9-21.9 / 105$ person years in HBsAg-negative and positive subjects, respectively. ${ }^{38} A$ recent study of a small group of surgically resected HCC patients at the National Cancer Institute, Bangkok reported a R249S mutation in 7/26 (27\%) cases, suggesting that the contribution of AFB1 to the burden of HCC in Thailand is far from negligible. ${ }^{39}$ In contrast, an earlier epidemiological study in Thailand using a albuminadduct biomarker to assess aflatoxin exposure failed to identify an aflatoxin associated risk for HCC. ${ }^{40}$

\section{Pesticides}

Pesticides exposure is one of the environmental factors hypothesized to increase the risk of HCC. Pesticides are considered to be possible epigenetic carcinogens through one or several mechanisms, such as spontaneous initiation of genetic changes, cytotoxicity with persistent cell proliferation, oxidative stress, inhibition of apoptosis, suppression of intracellular communication, and construction of activated receptors. ${ }^{41}$

A case-control study of HCC in HBV and/or HCV infected patients from Egypt suggested that pesticides have an additive effect on HCC risk in rural males, amongst whom the use of carbamate and organophosphate compounds is commonplace.

\section{Metabolic syndrome}

A population based study from the United States found diabetes to be an independent risk factor of HCC, regardless of chronic HCV or HBV infection, alcoholic liver disease, or nonspecific cirrhosis. Diabetes was associated with a two- to three-fold increase in $\mathrm{HCC}$ risk. About $60 \%$ of patients with $\mathrm{HCC}$ in this study were not diagnosed with chronic HCVrelated or HBV-related hepatitis, alcoholic liver disease, or other known causes of chronic liver disease. ${ }^{42}$ Among these patients, $47 \%$ had diabetes, which was higher than those with other risk factors $(41 \%)$. This suggested that diabetes may represent a considerable proportion of patients with idiopathic HCC. The rising prevalence of obesity and diabetes could be contributing to the increased incidence of HCC in the United States in the past three decades. Moreover, a study in Singapore demonstrated a statistically significant, positive association between diabetes status at baseline and elevated risk of developing HCC among Chinese, a population with relatively high prevalence of HBV infection and HCC incidence. ${ }^{43}$ This positive diabetes-HCC risk association in individuals without $\mathrm{CHB}$ or $\mathrm{CHC}$ suggested an independent role of diabetes in $\mathrm{HCC}$ development. Also, a Swedish study reported that there is a three-fold increased risk of liver cancer among patients hospitalized with diabetes and a four-fold increased risk in the presence of hepatitis, cirrhosis, and alcoholism. ${ }^{44}$ These findings have important implications in public health, given the worldwide rise in the incidence of type 2 diabetes.

Insulin resistance syndrome in diabetes has been implicated as a risk factor for nonalcoholic fatty liver disease (NAFLD), and nonalcoholic steatohepatitis (NASH) was identified as a cause of cryptogenic cirrhosis and HCC. Emerging evidence has established multiple independent risk factors for the development of HCC, including obesity, diabetes, and iron deposition. These factors also increase the risk for the development of $\mathrm{NASH}$, a probable precursor to cryptogenic cirrhosis. HCC can occur in noncirrhotic as well as cirrhotic NASH patients. ${ }^{45}$ The typical noncirrhotic NASH patient who presents with HCC tends to be older, male, and meets the criteria for one or more features of metabolic syndrome. ${ }^{46}$ The specific sequence of events leading to HCC in the setting of NASH is still under investigation, although certain key events have been determined. Insulin resistance and its subsequent inflammatory cascade that is associated with the development of NASH appear to play a significant role in the carcinogenesis of HCC. Insulin resistance associated with obesity, metabolic syndrome, and diabetes leads to increased release of free fatty acids from adipocytes, release of multiple proinflammatory cytokines (including tumor necrosis factor-alpha (TNF-a)), interleukin-6 (IL-6), leptin, and resistin and decreased amounts of adiponectin. These processes favor the development of hepatic steatosis and inflammation within the liver. ${ }^{47}$ Hyperinsulinemia may upregulate the production of insulin-like growth factor-1 (IGF1), a peptide hormone that stimulates growth through cellular proliferation and inhibition of apoptosis within the liver. ${ }^{48}$ Insulin also activates insulin receptor substrate-1 (IRS-1), which is involved in cytokine signaling pathways and has been shown to be upregulated in $\mathrm{HCC}^{49}$ The development of NASH is also associated with oxidative stress and the 
release of reactive oxygen species (ROS), which likely contributes to the development of HCC. Oxidative stress may favor tumorigenesis through steatosis, inflammation, and cell proliferation, or it may induce cancer-promoting mutations directly. The c-Jun amino-terminal kinase 1 (JNK1) has recently been linked to the development of obesity, insulin resistance, NASH, and HCC. JNK activation is also known to increase hepatic inflammation and apoptosis, ${ }^{50}$ JNK1 appears to be the most important kinase upregulated in HCC. ${ }^{51}$

The estimated national prevalence of diabetes in Thai adults was $9.6 \%$ (2.4 million people), where $4.8 \%$ were previously diagnosed and $4.8 \%$ were newly diagnosed. ${ }^{52}$ The rising prevalence of obesity and diabetes could a contributing factor for the increased incidence of HCC in Thailand over the past three decades.

\section{Conclusions}

Like many other developing countries, Thailand is currently undergoing an epidemiologic transition. As urbanization increases, so does environmental exposures and aging and life style changes; and it is likely that the incidence of HCC will continue to rise over the next few years. HBV infection, HBV infection with aflatoxin exposure, viral infection, alcohol consumption leading to overt cirrhosis of the liver, and alcohol consumption leading to cirrhosis of the liver with viral infection are predominant risk factors for the development of HCC in Thailand. The advent of mass-vaccination programs for hepatitis $B$ is beginning to reduce the prevalence rates for HCC. Other possible risk factors of HCC, such as DM and obesity, deserve more attention as the prevalence of these disorders increase worldwide. Our review helps to define the complex etiology of $\mathrm{HCC}$, which may enable policy makers to create targeted and more efficient prevention and screening programs.

\section{Conflict of interest}

None

\section{Author contributions}

Writing the paper (TC, KP).

\section{References}

[1] Khuhaprema T, Attasara P, Sriplung H, Wiangnon S, Sangrajrang S. Cancer in Thailand 2007-2009. Vol. VII. Bangkok: Bangkok Medical Publisher, 2013.

[2] Parkin DM, Whelan J, Ferlay J, Raymond L, Young J. Cancer Incidence in Five Continents, Vol. VII. IARC Scientific Publications No. 143. Lyon: International Agency for Research on Cancer, 1997;440-441.

[3] Poovorawan Y, Chongsrisawat V, Theamboonlers A, Leroux-Roels G, Kuriyakose S, Leyssen $\mathrm{M}$, et al. Evidence of protection against clinical and chronic hepatitis $B$ infection 20 years after infant vaccination in a high endemic city region. J Viral Hepat 2011;18:369-375. doi: $10.1111 / \mathrm{j} .1365$ 2893.2010.01312.x.

[4] Block TM, Mehta AS, Fimmel CJ, Jordan R. Molecular viral oncology of hepatocellular carcinoma. Oncogene 2003;22:5093-5107. doi: 10.1038/sj. onc. 1206557.

[5] Sooklim K, Sriplung H, Piratvisuth T. Histologic subtypes of hepatocellular carcinoma in the southern Thai population. Asian Pac J Cancer Prev 2003; 4:302-306

[6] Tangkijvanich P, Hirsch P, Theamboonlers A, Nuchprayoon I, Poovorawan Y. Association of hepatitis viruses with hepatocellular carcinoma in Thailand. J Gastroenterol 1999;34:227-233.
[7] Centers for Disease Control and Prevention (CDC). Global progress toward universal childhood hepatitis B vaccination, 2003. MMWR Morb Mortal Wkly Rep 2003;52:868-870.

[8] McMahon BJ. The natural history of chronic hepatitis B virus infection. Semin Liver Dis 2004;24:17-21. doi: 10.1055/s-2004-828674.

[9] Bruno S, Silini E, Crosignani A, Borzio F, Leandro G, Bono F, et al. Hepatitis C virus genotypes and risk of hepatocellular carcinoma in cirrhosis: a prospective study. Hepatology 1997;25:754-758. doi: 10.1002/hep.510250344.

[10] Michielsen PP, Francque SM, van Dongen JL. Viral hepatitis and hepatocellular carcinoma. World J Surg Oncol 2005;3:27. doi: 10.1186/1477-7819-327.

[11] Parkin DM, Bray F, Ferlay J, Pisani P. Estimating the world cancer burden: Globocan 2000. Int J Cancer 2001;94:153-156. doi: 10.1002/ijc.1440.

[12] Chang MH, Chen CJ, Lai MS, Hsu HM, Wu TC, Kong MS, et al. Universal hepatitis $B$ vaccination in Taiwan and the incidence of hepatocellular carcinoma in children. Taiwan Childhood Hepatoma Study Group. N Engl J Med 1997;336:1855-1859. doi: 10.1056/NEJM199706263362602.

[13] Murakami T, Baron RL, Peterson MS, Oliver JH 3rd, Davis PL, Confer SR, et al. Hepatocellular carcinoma: MR imaging with mangafodipir trisodium (Mn-DPDP). Radiology 1996;200:69-77.

[14] Liu CJ, Kao JH. Hepatitis B virus-related hepatocellular carcinoma: epidemiology and pathogenic role of viral factors. J Chin Med Assoc 2007; 70:141-145. doi: 10.1016/S1726-4901(09)70346-6.

[15] Moriya K, Fujie H, Shintani Y, Yotsuyanagi H, Tsutsumi T, Ishibashi K, et al. The core protein of hepatitis $C$ virus induces hepatocellular carcinoma in transgenic mice. Nat Med 1998;4:1065-1067. doi: 10.1038/2053.

[16] Tangkijvanich P, Mahachai V, Komolmit P, Fongsarun J, Theamboonlers A, Poovorawan Y. Hepatitis B virus genotypes and hepatocellular carcinoma in Thailand. World J Gastroenterol 2005;11:2238-2243. doi: 10.3748/wjg. v11.i15.2238.

[17] Chen CJ, Yang HI, Su J, Jen CL, You SL, Lu SN, et al. Risk of hepatocellular carcinoma across a biological gradient of serum hepatitis B virus DNA level. JAMA 2006;295:65-73. doi: 10.1001/jama.295.1.65.

[18] Chen CJ, Iloeje UH, Yang HI. Long-term outcomes in hepatitis B: the REVEAL-HBV study. Clin Liver Dis 2007;11:797-816. doi: 10.1016/j.cld. 2007.08.005.

[19] Verme G, Brunetto MR, Oliveri F, Baldi M, Forzani B, Piantino P, et al. Role of hepatitis delta virus infection in hepatocellular carcinoma. Dig Dis Sci 1991; 36:1134-1136.

[20] Suruki RY, Mueller N, Hayashi K, Harn D, DeGruttola V, Raker CA, et al. Host immune status and incidence of hepatocellular carcinoma among subjects infected with hepatitis $C$ virus: a nested case-control study in Japan. Cancer Epidemiol Biomarkers Prev 2006;15:2521-2525. doi: 10.1158/1055-9965. EPI-06-0485.

[21] Colombo M, Kuo G, Choo QL, Donato MF, Del Ninno E, Tommasini MA, et al. Prevalence of antibodies to hepatitis $C$ virus in Italian patients with hepatocellular carcinoma. Lancet $1989 ; 2: 1006-1008$. doi: 10.1016/S0140-6736 (89)91016-7.

[22] Fattovich G, Giustina G, Degos F, Tremolada F, Diodati G, Almasio P, et al. Morbidity and mortality in compensated cirrhosis type $\mathrm{C}$ : a retrospective follow-up study of 384 patients. Gastroenterology 1997;112:463-472. doi: 10.1053/gast.1997.v112.pm9024300.

[23] Hassan MM, Zaghloul AS, El-Serag HB, Soliman O, Patt YZ, Chappell CL, et al. The role of hepatitis $C$ in hepatocellular carcinoma: a case control study among Egyptian patients. J Clin Gastroenterol 2001;33:123-126.

[24] Kiyosawa K, Sodeyama T, Tanaka E, Gibo Y, Yoshizawa K, Nakano Y, et al. Interrelationship of blood transfusion, non- $A$, non-B hepatitis and hepatocellular carcinoma: analysis by detection of antibody to hepatitis $C$ virus. Hepatology 1990;12:671-675.

[25] Tong MJ, el-Farra NS, Reikes AR, Co RL. Clinical outcomes after transfusionassociated hepatitis C. N Engl J Med 1995;332:1463-1466. doi: 10. 1056/NEJM199506013322202.

[26] Ahn J, Flamm SL. Hepatocellular carcinoma. Dis Mon 2004;50:556-573. doi: 10.1016/j.disamonth.2004.10.001.

[27] Khan MH, Farrell GC, Byth K, Lin R, Weltman M, George J, et al. Which patients with hepatitis $C$ develop liver complications? Hepatology 2000;1: 513-520. doi: 10.1002/hep.510310236.

[28] Gower E, Estes C, Blach S, Razavi-Shearer K, Razavi H. Global epidemiology and genotype distribution of the hepatitis $C$ virus infection. J Hepatol 2014; 61:S45-S57. doi: 10.1016/j.jhep.2014.07.027.

[29] Punyagupta S, Jidpugdeebodin S, Siwadune. Hepatitis C infection and hepatocellular carcinoma in Thailand: A long term study of $63 \mathrm{HCV}$ patients. $\mathrm{J}$ Infect Dis Antimicrob Agents 1999;16:1-5.

[30] Chiaramonte M, Stroffolini T, Vian A, Stazi MA, Floreani A, Lorenzoni U, et al. Rate of incidence of hepatocellular carcinoma in patients with compensated viral cirrhosis. Cancer 1999;85:2132-2137.

[31] Donato F, Boffetta P, Puoti M. A meta-analysis of epidemiological studies on the combined effect of hepatitis $B$ and $C$ virus infections in causing hepatocellular carcinoma. Int J Cancer 1998;75:347-354. 
[32] Garcia-Samaniego ], Rodriguez M, Berenguer ], Rodriguez-Rosado R, Carbo J, Asensi $\mathrm{V}$, et al. Hepatocellular carcinoma in HIV-infected patients with chronic hepatitis C. Am J Gastroenterol 2001;96:179-183. doi: 10.1111/j.15720241.2001.03374.x.

[33] El-Serag HB, Rudolph KL. Hepatocellular carcinoma: epidemiology and molecular carcinogenesis. Gastroenterology 2007;132:2557-2576. doi: 10.1053/j. gastro.2007.04.061.

[34] Braga C, La Vecchia C, Negri E, Franceschi S. Attributable risks for hepatocellular carcinoma in northern Italy. Eur J Cancer 1997;33:629-634. doi: 10.1016/S0959-8049(96)00500-X.

[35] Donato F, Tagger A, Chiesa R, Ribero ML, Tomasoni V, Fasola M, et al. Hepatitis $B$ and $C$ virus infection, alcohol drinking, and hepatocellular carcinoma: a casecontrol study in Italy. Brescia HCC Study. Hepatology 1997;26: 579-584. doi: 10.1002/hep.510260308.

[36] Jepsen P, Ott P, Andersen PK, Sørensen HT, Vilstrup H. Risk for hepatocellular carcinoma in patients with alcoholic cirrhosis: a Danish nationwide cohort study. Ann Intern Med 2012;156:841-847. doi: 10.7326/0003-4819-15612-201206190-00004.

[37] Besaratinia A, Kim SI, Hainaut P, Pfeifer GP. In vitro recapitulating of TP53 mutagenesis in hepatocellular carcinoma associated with dietary aflatoxin B1 exposure. Gastroenterology 2009;137:1127-1137. e1-e5. doi: 10.1053/ j. gastro.2009.06.002.

[38] Liu Y, Wu F. Global burden of aflatoxin-induced hepatocellular carcinoma: a risk assessment. Environ Health Perspect 2010;118:818-824. doi: 10.1289/ehp. 0901388.

[39] Galy O, Chemin I, Le RE, Villar S, Le Calvez-Kelm F, Lereau M, et al. Mutations in TP53 and CTNNB1 in Relation to Hepatitis B and C Infections in Hepatocellular Carcinomas from Thailand. Hepat Res Treat 2011;2011:697162. doi: $10.1155 / 2011 / 697162$.

[40] Srivatanakul P, Parkin DM, Khlat M, Chenvidhya D, Chotiwan P, Insiripong S, et al. Liver cancer in Thailand. II. A case-control study of hepatocellular carcinoma. Int J Cancer 1991;48:329-332.

[41] El-Ghorory L, Mikhail NN, Abdel-Hamid A, Hifnawy T, Strickland GT, Loffredo $\mathrm{CA}$. Associations of pesticides, $\mathrm{HCV}, \mathrm{HBV}$, and hepatocellular carcinoma in Egypt. Int J Hyg Environ Health 2005;208:329-339.
[42] Davila JA, Morgan RO, Shaib Y, McGlynn KA, El-Serag HB. Diabetes increases the risk of hepatocellular carcinoma in the United States: a population based case control study. Gut 2005;54:533-539. doi: 10.1136/gut.2004.052167.

[43] Koh WP, Wang R, Jin A, Yu MC, Yuan JM. Diabetes mellitus and risk of hepatocellular carcinoma: findings from the Singapore Chinese Health Study. Br J Cancer 2013;108:1182-1188. doi: 10.1038/bjc.2013.25.

[44] Adami HO, Chow WH, Nyren O, Berne C, Linet MS, Ekbom A, et al. Excess risk of primary liver cancer in patients with diabetes mellitus. J Natl Cancer Inst 1996;88:1472-1477. doi: 10.1093/jnci/88.20.1472.

[45] Torres DM, Harrison SA. Nonalcoholic steatohepatitis and noncirrhotic hepatocellular carcinoma: fertile soil. Semin Liver Dis 2012;32:30-38. doi: 10.1055/s-0032-1306424.

[46] Starley BQ, Calcagno CJ, Harrison SA. Nonalcoholic fatty liver disease and hepatocellular carcinoma: a weighty connection. Hepatology 2010;51: 1820-1832. doi: 10.1002/hep. 23594.

[47] Harrison SA. Liver disease in patients with diabetes mellitus. J Clin Gastroenterol 2006;40:68-76.

[48] Calle EE, Kaaks S. Overweight, obesity and cancer: epidemiological evidence and proposed mechanisms. Nat Rev Cancer 2004;4:579-591. doi: $10.1038 / \mathrm{nrc1} 408$.

[49] Tanaka S, Mohr L, Schmidt EV, Suqimachi K, Wands JR. Biological effects of human insulin receptor substrate-1 overexpression in hepatocytes. Hepatology 1997;26:598-604. doi: 10.1002/hep.510260310.

[50] Puri P, Mirshahi F, Cheung O, Natarajan R, Maher JW, Kellum JM, et al. Activation and dysregulation of the unfolded protein response in nonalcoholic fatty liver disease. Gastroenterology 2008;134:568-576. doi: 10.1053/j. gastro.2007.10.039.

[51] Chen F, Beezhold K, Castranova V. JNK1, a potential therapeutic target for hepatocellular carcinoma. Biochim Biophys Acta 2009;1796:242-251. doi: 10.1016/j.bbcan.2009.06.005.

[52] Aekplakorn W, Stolk RP, Neal B, Suriyawongpaisal $P$, Chongsuvivatwong $V$ Cheepudomwit $\mathrm{S}$, et al. INTERASIA Collaborative Group. The prevalence and management of diabetes in Thai adults: the international collaborative study of cardiovascular disease in Asia. Diabetes Care 2003;26:2758-2763. doi: 10.2337/diacare.26.10.2758 